\title{
Comparative Evaluation of Hydrophobic and Hydrophilic Resin-based Sealants: A Clinical Study
}

\author{
Madhumitha Mohanraj ${ }^{1}$, Rathna Prabhu², Eapen Thomas ${ }^{3}$, Senthil Kumar ${ }^{4}$
}

\begin{abstract}
Aim: The purpose of this study is to clinically evaluate and compare the retention and evidence of caries of three fissure sealants. Materials and methods: A total of 150 children, between 7 and 13 years of age, with fully erupted permanent molars, had sealants placed using a full-mouth design. Sealant retention was evaluated at 1, 3, 6, 9, and 12 months later. Teeth were evaluated for retention and evidence of caries using Simonsen's criteria and results were subjected to statistical analysis using the Chi-square test.

Results: At 1-year examination, in teeth sealed with Clinpro: (a) $8 \%$ were completely retained, (b) $74.4 \%$ were partially lost, and (c) $8.5 \%$ were completely lost; with Embrace Wetbond: (a) none of the sealants were completely retained, (b) $13.1 \%$ were partially lost, and (c) $59.1 \%$ were completely lost; with Champ: (a) $1 \%$ were completely retained, (b) $71.4 \%$ were partially lost, and (c) $10.9 \%$ were completely lost. All the three sealants showed evidence of caries from 9 months.

Conclusion: The retention of hydrophobic (Clinpro) sealant was superior to hydrophilic (Embrace Wetbond and Champ) sealants. The evidence of caries was less in the hydrophobic sealant group when compared with the hydrophilic sealant groups. There was no statistical difference in retention and evidence of caries between maxillary and mandibular teeth for all the three sealant groups.

Clinical significance: Sealants prevent the occurrence of caries in the majority of children. Though hydrophobic sealants appear to be more successful, hydrophilic sealants too may provide promising results in the near future.

Keywords: Caries evidence, Pit and fissure sealants, Retention.

The Journal of Contemporary Dental Practice (2019): 10.5005/jp-journals-10024-2602
\end{abstract}

\section{INTRODUCTION}

Modern dentistry plays an important role in the prevention of caries and, hence, the original concept of "extension for prevention" has been changed to a minimal intervention approach. Although occlusal surfaces constitute only $12.5 \%$ of the total tooth surfaces, they have shown to develop more than two-thirds of the total caries experienced by children.'

Fluorides are considered to be very useful in preventing dental caries, but their effectiveness is reduced on the occlusal surfaces, especially the pits and fissures where $90 \%$ of caries occur. ${ }^{2}$ This is especially true for newly erupted permanent molars due to their complex anatomic occlusal morphology with deep, narrow pits and fissures which act as a niche for dental plaque accumulation. ${ }^{3}$ These areas are difficult to access for cleaning procedures and the incomplete maturation of enamel adds to caries susceptibility. ${ }^{4}$ Hence, the most effective, efficient, and safest means of preventing caries in the pits and fissures of newly erupted permanent teeth is the application of pit and fissure sealants.

The discovery of etching of enamel with phosphoric acid to increase the retention and marginal integrity of resin restorative materials led to the development of pit and fissure sealants. It was Michael Buonocore who published the first paper on the application of sealants to pits and fissures, which lead to a major breakthrough in preventive dentistry. ${ }^{5}$ Pit and fissure sealants when introduced into the pits and fissures of caries susceptible teeth form a micromechanically bonded protective layer, cutting access of caries-producing bacteria from their source of nutrients. ${ }^{6}$

Since the introduction of the first dental sealant Nuva Seal in 1971, a wide range of newer sealant materials are available today. The resinbased sealant technology has also advanced to include a moisture tolerant chemistry. While the traditional sealants are hydrophobic, the
${ }^{1,4}$ Department of Pediatric and Preventive Dentistry, RVS Dental College and Hospital, Coimbatore, Tamil Nadu, India

${ }^{2}$ Kanchi Kamakoti Child Trust Hospital, Chennai, Tamil Nadu, India ${ }^{3} \mathrm{NMC}$ Dental Clinic, Sharjah, United Arab Emirates

Corresponding Author: Madhumitha Mohanraj, Department of Pediatric and Preventive Dentistry, RVS Dental College and Hospital, Coimbatore, Tamil Nadu, India, Phone: +91 9894400305, e-mail: madhumithakarthik@ gmail.com

How to cite this article: Mohanraj M, Prabhu R, et al. Comparative Evaluation of Hydrophobic and Hydrophilic Resin-based Sealants: A Clinical Study. J Contemp Dent Pract 2019;20(7):812-817.

Source of support: Nil

Conflict of interest: None

unique moisture tolerant sealants are hydrophilic in nature. Hence, they are miscible with water and flow into moisture-containing etched enamel creating a strong bond for better retention. ${ }^{7}$

In the Pediatric and Preventive Dentistry, fissure sealant retention is identified as the most important outcome measure of quality. Placement of sealant is highly technique sensitive and their success depends on adequate moisture control during application and their long-time retention. It evaluates both the technical process and the outcome of care delivered. ${ }^{8}$ Moreover, the effectiveness of sealants in preventing caries is also known to depend on their retention. The first report evaluating sealant retention over a significant period of 5 years was Horowitz's landmark Kalispell study (1976). However, the longest possible retention of sealants was reported by Simonsen as between 10 and 15 years. ${ }^{6}$ Ruta $^{9}$ reported that the retention rate of sealants on the first permanent molars appear to be high within 5 years. 
Though there are numerous studies on the retention of different sealant materials, there are only very limited studies on the retention and evidence of caries in moisture-tolerant sealant-treated teeth. Hence, this study was done to evaluate and compare the retention and evidence of caries in teeth treated with conventional and moisture-tolerant sealants.

\section{Materials and Methods}

The study was carried out at the Department of Pedodontics and Preventive Dentistry and was approved by the Institutional Review Board after Ethical Committee clearance. A total of 150, 7-13-yearold healthy cooperative children (600 teeth) with completely erupted all four permanent molars with deep pits and fissures in the high-risk caries group were included in the study. Moreover, the selected teeth should be caries free and untreated. Children with hypoplastic first permanent molars or developmental anomalies were excluded from the study. Informed consent from their respective parents and school authorities was obtained.

A thorough oral prophylaxis was done, followed by polishing using a slurry of pumice and rotating brush to ensure removal of debris from pits and fissures. The teeth to be treated were rinsed followed by drying and isolation with a rubber dam and a saliva ejector.

All the sealants were placed by a single operator under proper illumination. Children were randomly divided into three groups, 50 children were included in each group with a total of 200 teeth per group; group I: Clinpro (3 M ESPE, USA)—hydrophobic sealant; group II: Embrace Wetbond (Pulpdent Corporation, USA) - hydrophilic sealant; and group III: Champ (Centrix, USA)—-hydrophilic sealant.

The surface of the teeth was etched with $37 \%$ of phosphoric acid for 30 seconds and then thoroughly rinsed with water spray for 30 seconds for complete removal of etchant and air dried until the enamel had a white frosty appearance in the Clinpro group, whereas in Embrace Wetbond and Champ groups, the teeth surfaces were left slightly moist with a glossy appearance. No bonding agents were applied for all the three sealant groups. Sealants were applied according to the manufacturer's instructions.

The children were recalled after a time interval of $1,3,6,9$, and 12 months to evaluate the retention and evidence of caries using Simonsen's criteria. The evaluation was done by the use of the visual-tactile method using a mouth mirror and an explorer. All the follow-up examinations were done by a single examiner who was blinded to the materials used. The data obtained were tabulated and the results were subjected to statistical analysis using the Chi-square test with a statistical significance of $p<0.05$ or $95 \% \mathrm{Cl}$.

\section{Simonsen's Scoring Criteria}

Score 0: No loss of sealant and no evidence of caries.

Score 1: Partial loss of sealant and no evidence of caries.

Score 2: Partial loss of sealant and evidence of caries.

Score 3: Complete loss of sealant and no evidence of caries.

Score 4: Complete loss of sealant and evidence of caries.

\section{Results}

The results of this study showed that at 3 months, all the three sealant groups had a similar amount of no loss (80\%, 80\%, and $81 \%)$ and partial loss (20\%, $16 \%$, and $18.5 \%)$. At 6 months, nearly $70 \%$ of the sealants in all the three groups were completely retained and nearly $25 \%$ were partially retained.
Table 1: Intergroup comparison of sealant retention

\begin{tabular}{|c|c|c|c|c|}
\hline Time point & Sealant state & $\begin{array}{l}\text { Clinpro vs } \\
\text { Embrace } \\
\text { WetBond } \\
\text { p value }\end{array}$ & $\begin{array}{l}\text { Clinpro } \\
\text { vs Champ } \\
p \text { value }\end{array}$ & $\begin{array}{l}\text { Embrace } \\
\text { WetBond } \\
\text { vs Champ } \\
\text { p value }\end{array}$ \\
\hline \multirow[t]{3}{*}{1 month } & No loss & 0.092 & 0.319 & 0.485 \\
\hline & Partial loss & 0.092 & 0.319 & 0.485 \\
\hline & Complete loss & - & - & - \\
\hline \multirow[t]{3}{*}{3 months } & No loss & 1.000 & 0.801 & 0.801 \\
\hline & Partial loss & 0.298 & 0.704 & 0.508 \\
\hline & Complete loss & $0.004^{*}$ & 0.317 & $0.018^{*}$ \\
\hline \multirow[t]{3}{*}{6 months } & No loss & 0.339 & 0.914 & 0.288 \\
\hline & Partial loss & 0.111 & 0.579 & 0.297 \\
\hline & Complete loss & $<0.001^{* *}$ & 0.200 & $0.001^{*}$ \\
\hline \multirow[t]{3}{*}{9 months } & No loss & $<0.001^{* *}$ & $<0.001^{* *}$ & $0.044^{*}$ \\
\hline & Partial loss & $<0.001^{* *}$ & 0.095 & $<0.001^{* *}$ \\
\hline & Complete loss & $<0.001^{* *}$ & 0.654 & $<0.001^{* *}$ \\
\hline \multirow[t]{3}{*}{12 Months } & No loss & $<0.001^{* *}$ & $0.001^{*}$ & 0.175 \\
\hline & Partial loss & $<0.001^{* *}$ & 0.507 & $<0.001^{* *}$ \\
\hline & Complete loss & $<0.001^{* *}$ & 0.436 & $<0.001^{* *}$ \\
\hline
\end{tabular}

${ }^{*} p<0.05$ is significant; ${ }^{* *} p<0.001$ is highly significant

At 9 months in our study, only $20 \%$ of sealants were completely retained in the Clinpro group, whereas a meager of $2 \%$ in the Champ group and surprisingly none of the sealants were retained in the Embrace Wetbond group. Nearly $58.7 \%$ of the sealants were completely lost in the Embrace Wet Bond group, with only $6.5 \%$ and 7.5\% completely lost in Clinpro and Champ groups, respectively.

At the end of 1 year, either completely or partially retained sealants were nearly $82 \%$ in the Clinpro group and $72 \%$ in the Champ group (Table 1 and Fig. 1).

Evidence of caries was present only at 9 months. At both 9 and 12 months, the percentage of caries in the Clinpro group (5\% and $9.1 \%$, respectively) was much less than that seen in the Embrace Wetbond (16.9\% and $27.8 \%$ respectively) and Champ groups (14.3\% and $16.7 \%$, respectively) (Table 2 and Fig. 2).

There was no statistical difference in retention and evidence of caries between maxillary and mandibular teeth sealed with any of the three sealants (Figs 3 to 5).

\section{Discussion}

As sealants act as a physical barrier to decay, protection is determined by the sealants ability to adhere well to the tooth surface and, hence, clinical retention became the measure of sealant success. ${ }^{10}$ Clinical evidence suggests that sealant loss occurs in two phases: there is an initial loss due to a faulty technique such as moisture contamination, followed by a second loss associated with material wear under the forces of occlusion. ${ }^{11}$ Sealant loss may be due to inadequate sealing of all the pits/fissures, inadequate etching, rinsing, drying, insufficient curing time, ${ }^{12}$ position of tooth in the mouth, state of tooth eruption, ${ }^{13}$ tooth morphology, caries risk, oral hygiene habits, ${ }^{14}$ skill of the operator, placement technique, ${ }^{13,15,16}$ and age of the patient. ${ }^{13,15,17}$

Higher retention rates reported in other studies may either be due to reapplication of the sealants in between once they are lost, $4,9,11,18,19$ or may be due to mechanical preparation of pits and fissures. ${ }^{20,21}$ 


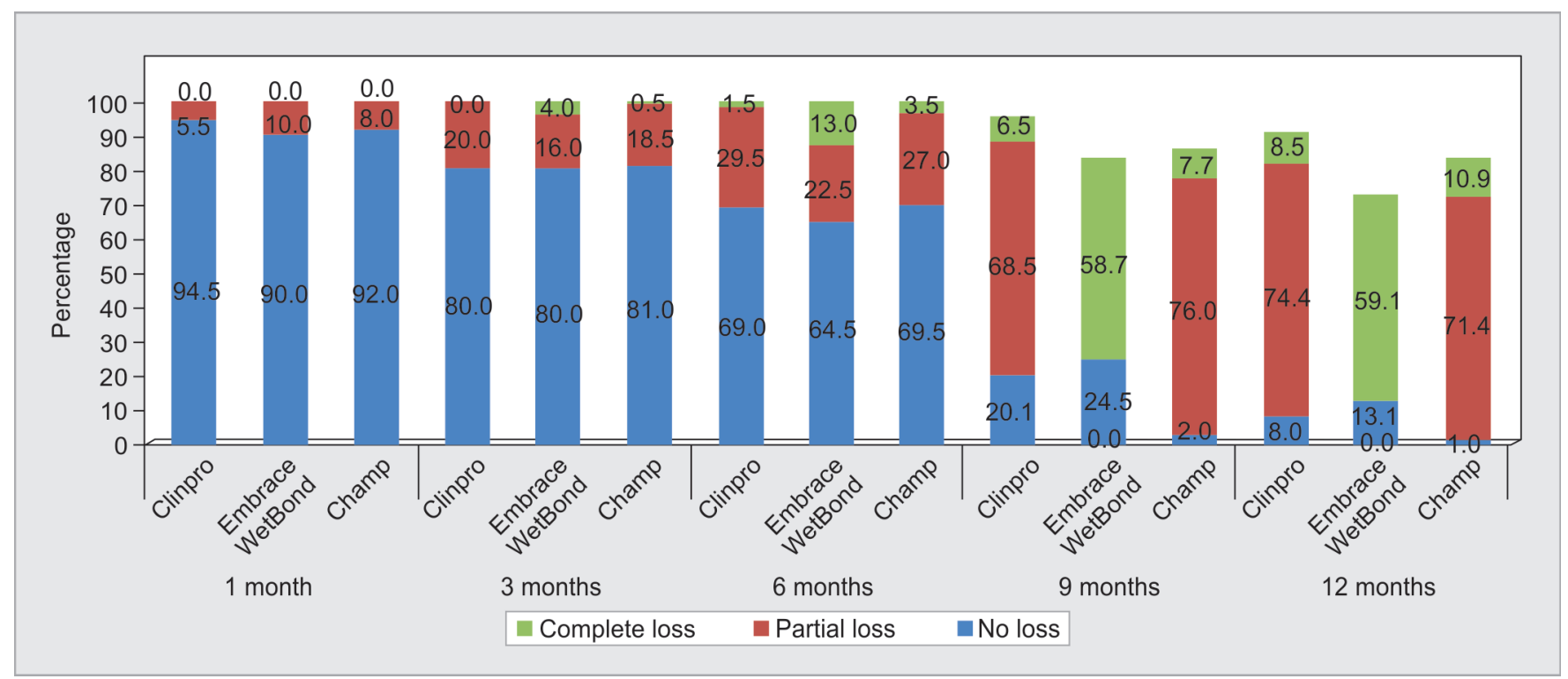

Fig. 1: Sealant retention

In our study, sealants were applied to children in the age group of 7-13 years, and lost sealants were not reapplied in between as our intention was also to evaluate whether there was caries development when sealants were partially or completely lost in the following reviews, which might also have been a contributing factor for more sealant loss at the end of 1 year than reported in other studies where sealants were reapplied. Another possible reason is the method of evaluating sealant loss as completely retained, partial, or complete loss. In most of the studies, even if sealants were partially lost from any of the fissures, they were considered as

Table 2: Intergroup comparison of caries development

\begin{tabular}{|c|c|c|c|c|}
\hline Time point & Sealant state & $\begin{array}{l}\text { Clinpro vs } \\
\text { Embrace } \\
\text { WetBond, } \\
p \text { value }\end{array}$ & $\begin{array}{l}\text { Clinpro vs } \\
\text { Champ, } p \\
\text { value }\end{array}$ & $\begin{array}{l}\text { Embrace } \\
\text { WetBond } \\
\text { vs Champ, } \\
\text { p value }\end{array}$ \\
\hline \multirow[t]{2}{*}{1 month } & $\begin{array}{l}\text { Partial loss with } \\
\text { evidence of caries }\end{array}$ & - & - & - \\
\hline & $\begin{array}{l}\text { Complete loss with } \\
\text { evidence of caries }\end{array}$ & - & - & - \\
\hline \multirow[t]{2}{*}{3 months } & $\begin{array}{l}\text { Partial loss with } \\
\text { evidence of caries }\end{array}$ & - & - & - \\
\hline & $\begin{array}{l}\text { Complete loss with } \\
\text { evidence of caries }\end{array}$ & - & - & - \\
\hline \multirow[t]{2}{*}{6 months } & $\begin{array}{l}\text { Partial loss with } \\
\text { evidence of caries }\end{array}$ & - & - & - \\
\hline & $\begin{array}{l}\text { Complete loss with } \\
\text { evidence of caries }\end{array}$ & - & - & - \\
\hline \multirow[t]{2}{*}{9 months } & $\begin{array}{l}\text { Partial loss with } \\
\text { evidence of caries }\end{array}$ & 0.806 & $0.031^{*}$ & $0.018^{*}$ \\
\hline & $\begin{array}{l}\text { Complete loss with } \\
\text { evidence of caries }\end{array}$ & $<0.001^{* *}$ & $0.027^{*}$ & $0.006^{*}$ \\
\hline \multirow[t]{2}{*}{12 months } & $\begin{array}{l}\text { Partial loss with } \\
\text { evidence of caries }\end{array}$ & 0.357 & 0.288 & $0.049^{*}$ \\
\hline & $\begin{array}{l}\text { Complete loss with } \\
\text { evidence of caries }\end{array}$ & $<0.001^{* *}$ & $0.040^{*}$ & $<0.001^{* *}$ \\
\hline
\end{tabular}

${ }^{*} p<0.05$ is significant; ${ }^{* *} p<0.001$ is highly significant

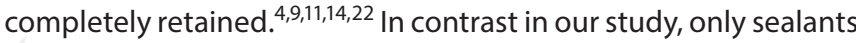
that were completely retained in all the pits and fissures were considered for no loss and sealants that were lost even partially from any of the fissures were considered as partially lost. This might have projected a more percentage of sealant loss.

Moreover, the difference in diet, dental health awareness, and the use of indigenous oral hygiene practices could be attributed to the early loss of sealants. Though dental education, diet counseling, and oral hygiene instructions were given and constantly reinforced during each recall visit, lack of indigenous oral hygiene practices cannot be ruled out as a confounding and possible cause for early loss or defects, despite the use of proper techniques and isolation methods. ${ }^{23}$

When comparing the three sealants, at the end of 1 year, the Embrace Wetbond group was found to have the worst retention. The possible reasons may be, first, Embrace Wetbond is a filled, fluoride-containing sealant. Several studies have reported lower retention rates in teeth sealed with filled resins. ${ }^{24-27}$ This might be due to poor marginal adaptation and more percentage of filler particles leading to higher viscosity of the material. Higher viscosity may cause poorer adaptation and incomplete penetration up to the bottom of the pit and fissures resulting in decreased retention. ${ }^{28}$

Second, Embrace Wetbond applied in this study was a naturalshade sealant material and, hence, it was difficult to identify the sealant both during application and also during reevaluation.

Evidence of caries was seen only at 9 months. This may be due to the high percentage of sealant loss, as the effectiveness of sealants in preventing caries depends on their retention. ${ }^{8}$ At both 9 and 12 months, the percentage of caries in the Clinpro group ( $5 \%$ and $9.1 \%$, respectively) was much less than that seen in the Embrace Wetbond (16.9\% and $27.8 \%$, respectively) and Champ groups (14.3\% and $16.7 \%$, respectively). This may be due to sealant retention at the base of the fissures in the Clinpro group, having a least amount of filler particles and, hence, lesser viscosity, leading to better penetration up to the depth of the fissures. These results were in accordance with Messer et al., ${ }^{11}$ who had used an unfilled resin sealant and reported $10 \%$ of caries development at the end of 1 year. 


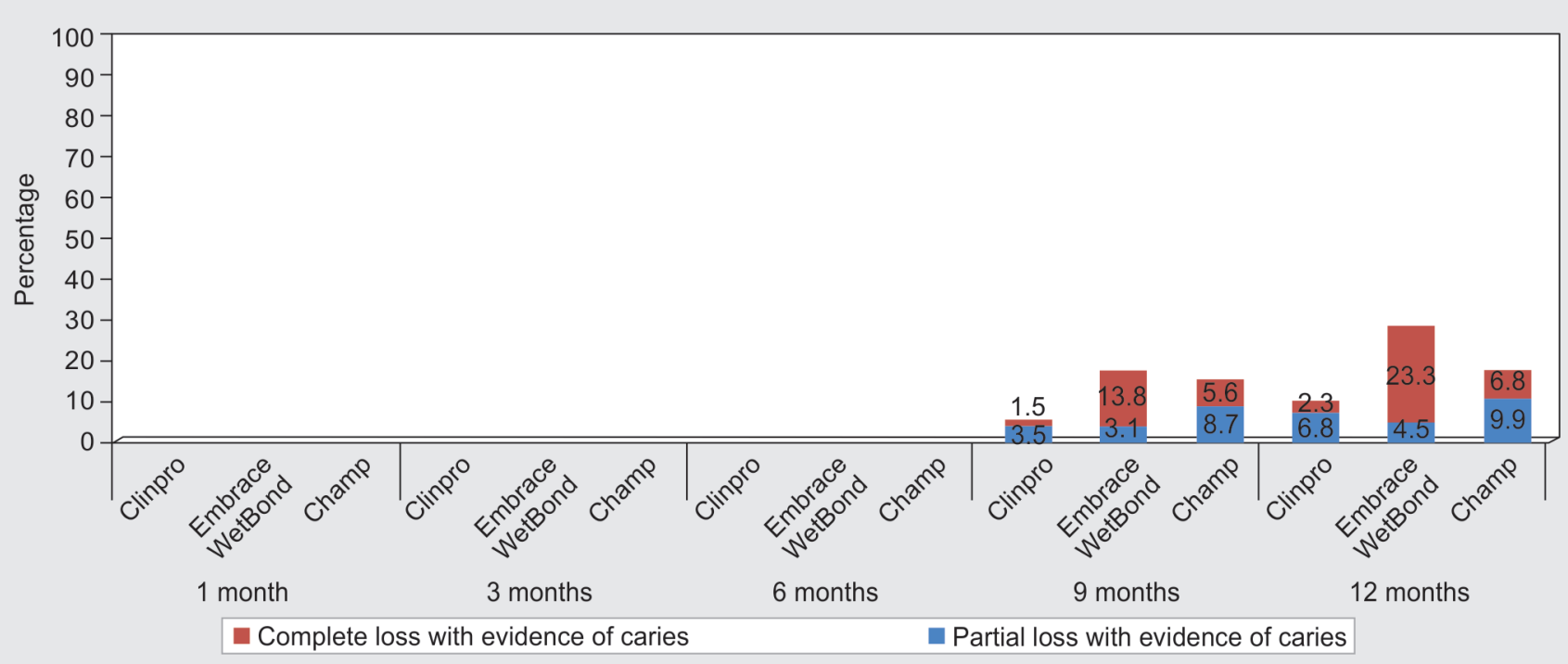

Fig. 2: Evidence of caries

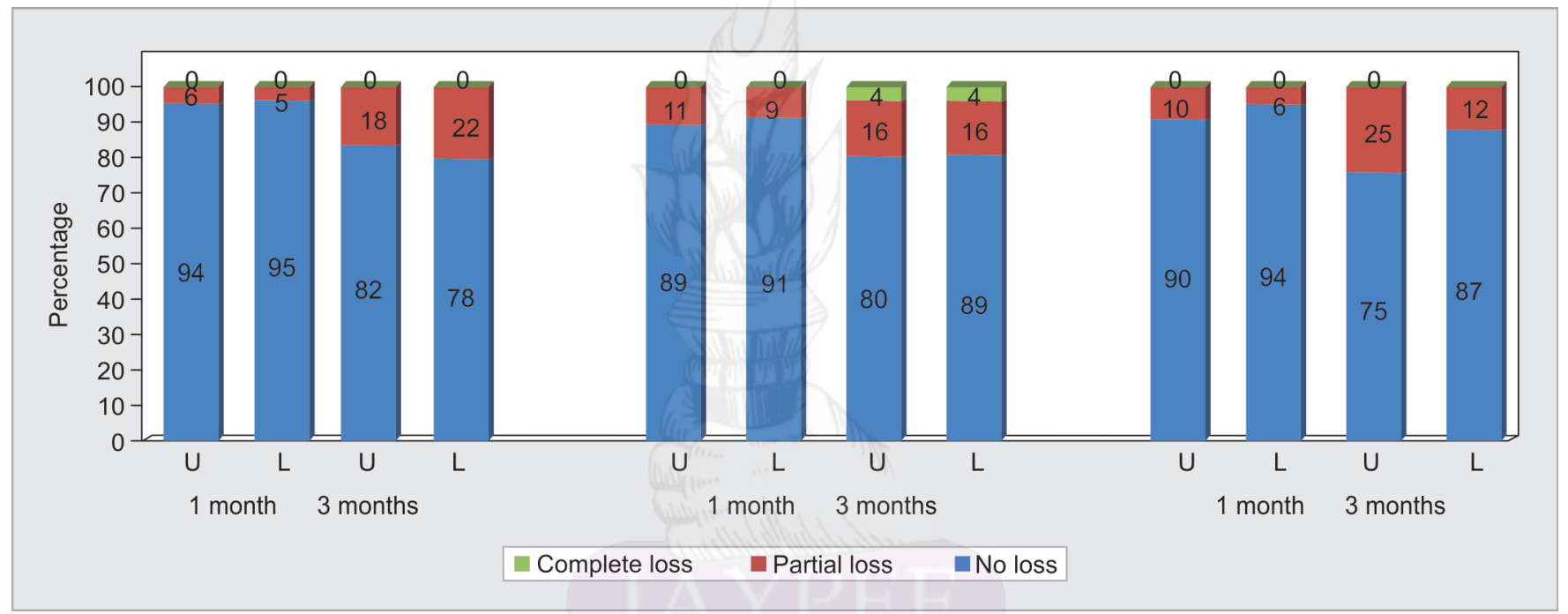

Fig. 3: Retention between maxillary and mandibular teeth -1 and 3 months

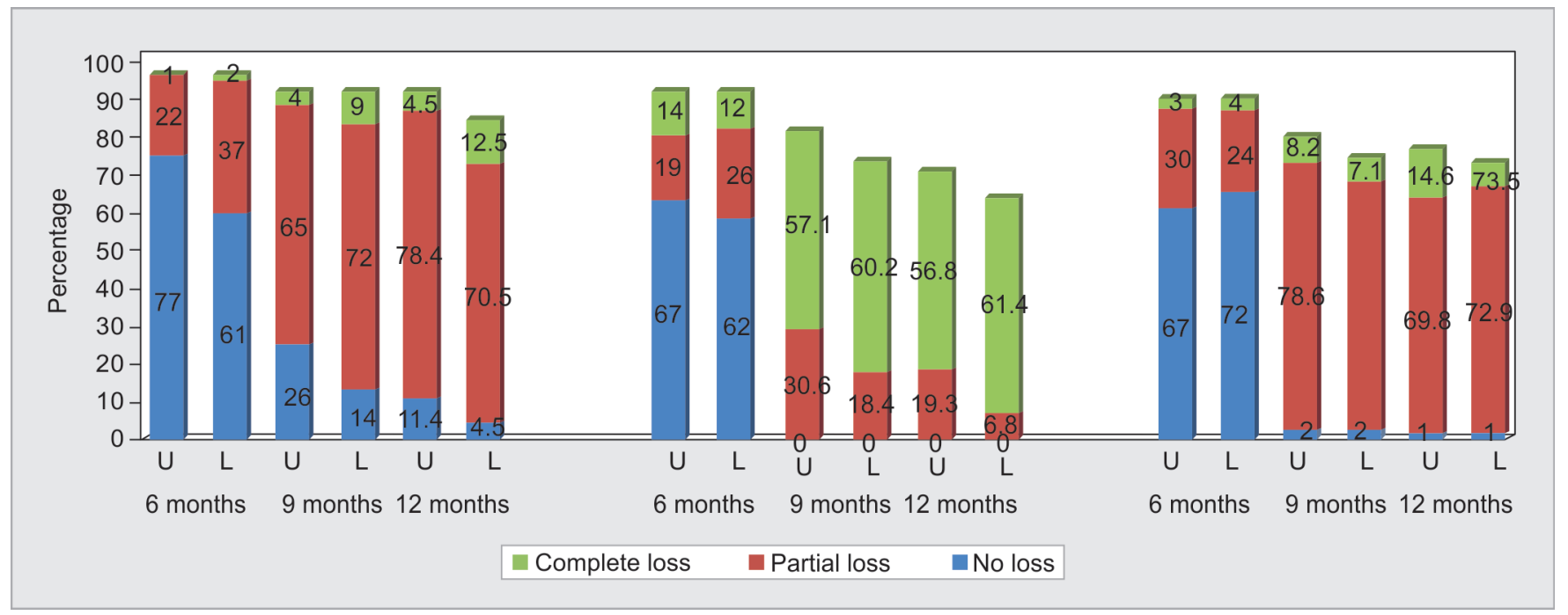

Fig. 4: Retention between maxillary and mandibular teeth-6, 9, and 12 months 


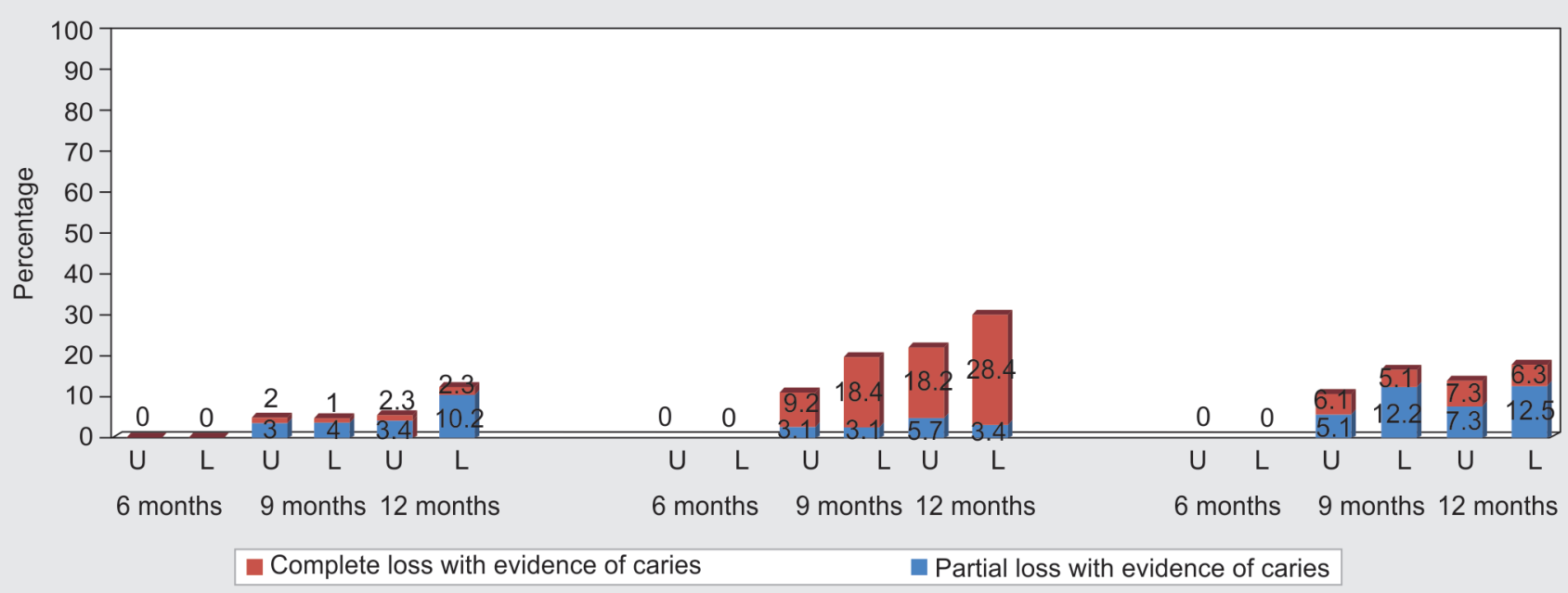

Fig. 5: Evidence of caries between maxillary and mandibular teeth

The possible reason for the Embrace WetBond group having a higher incidence of caries development than the Champ group is that it is a filled resin with a high filler content of $36.6 \%$ compared to $5 \%$ of the Champ. Therefore, the penetration of Champ into the fissures might have been better than that of Embrace Wetbond.

Even though all the three groups contained fluoride, the caries protective action in pits and fissures may be due to the action of fluoride at the base of the fissures.

An additional reason for more caries development in Embrace Wetbond may be due to the change in surface characteristics observed in filled resins, as rough surfaces and margins eventually may contribute to plaque retention and caries development.

Comparing the retention and caries development between maxillary and mandibular teeth, there was no statistical difference at the end of 1 year. This is in accordance with the clinical survey done by Messer et al. ${ }^{11}$ who reported equal losses between both the maxillary and mandibular molars. In contrast, Francis ${ }^{29}$ and Nupur ${ }^{3}$ have concluded higher retention rates with maxillary teeth when compared to mandibular teeth. However, mandibular teeth with higher retention rates than maxillary teeth were reported in other studies. ${ }^{1,30}$

Despite the fall in retention rates, the unfilled, colored hydrophobic sealant (Clinpro) performed better than the filled hydrophilic sealants (Embrace WetBond and Champ). The development of hydrophilic sealants is promising. Further research and the development of an unfilled hydrophilic sealant can overcome the drawbacks of a filled hydrophilic sealant.

Proper assessments of caries risk and recall at a specified time interval play an important part in preventive strategy during which sealants are to be reevaluated and reapplied if necessary.

\section{CONCLUSION}

Based on this study result, the following conclusions can be made

- The retention of the hydrophobic-unfilled sealant-Clinpro (3M ESPE) was superior to the two hydrophilic-filled sealants Embrace Wetbond (Pulpdent corporation) and Champ (Centrix).

- Among the hydrophilic sealants, Champ sealant retention was better than Embrace WetBond.
- The evidence of caries was less in the Clinpro group followed by the Champ and Embrace Wetbond groups.

- There was no statistical difference in retention and evidence of caries between maxillary and mandibular teeth for all the three sealants.

\section{Clinical Significance}

Sealants prevent the occurrence of occlusal caries in the majority of children. Though hydrophobic sealants appear to be more successful, hydrophilic sealants too may provide promising results in the prevention of dental caries in the near future.

\section{Authors' contributions}

All authors have made a substantive contribution to this study and/or manuscript, and all have reviewed the final paper prior to its submission.

\section{ACKNOWLedgments}

The authors would like to thank Dr R Senthil for his valuable guidance and all the patients and their parents for their cooperation during this follow-up study.

\section{References}

1. Jaberi Ansari Z, Hashemi SM. Effect of enamel bonding agents on pit and fissure sealant retention in an isolated situation. J Dent 2008;5(4):156-160.

2. Michael A, Ignelzi JR. Pit and fissure sealants - An ongoing commitment. J Calif Dent Assoc 2010;8(10):725-728.

3. Nupur N, Nayak Anand U, et al. A 1-year evaluation of pit and fissure sealants on permanent first molars. Contemp Clin Dent 2012;3(1): 54-59. DOI: 10.4103/0976-237X.94547.

4. Arzu P, Elif $S$, et al. Clinical performance of sealants with and without a bonding agent. Quintessence Int 2005;36(5):355-360.

5. Stanley LH, Zia S. Michael Buonocore and the Eastman dental center: a historic perspective on sealants. J Dent Res 1996;75(1):529-534. DOI: 10.1177/00220345960750010401.

6. Simonsen, RJ. Pit and fissure sealants. In: Clinical applications of the acid etch technique, 1st ed. Chicago, IL: Quintessence publishing Co, Inc, 1978; pp. 19-42. 
7. Howard ES, Joseph P. A unique moisture-tolerant resin based pit and fissure sealant-Clinical technique and research results. Inside Dentistry 2008;4(9):2-3.

8. Ana Karina M, Amr MM. Use of fissure sealant retention as an outcome measure in a dental school setting. J Dent Educ 2001;65(9):861-865.

9. Ruta B, Vytaute $P$, et al. A five years clinical evaluation of sealed occlusal surfaces of molars. Stomatologija: Baltic Dental and Maxillofacial Journal 2010;12(3):87-92.

10. William FW, Mark S. Pit and fissure sealant application: updating the technique. J Am Dent Assoc 1996;127:351-361. DOI: 10.14219/jada. archive.1996.0205.

11. Louise Brearley M, Hanny $C$, et al. The retention of pit and fissure sealants placed in primary school children by dental health services, Victoria. Aust Dent J 1997;42(4):233-239. DOI: 10.1111/j.1834-7819.1997. tb00127.x.

12. Anson RA, Full CA, et al. Retention of pit and fissure sealants placed in a dental school pedodontic clinic: A retrospective study. Pediatr Dent 1982;4:22-26.

13. Parnell CA, Farrell $\mathrm{MO}$, et al. Evaluation of a community fissure sealant programme in County Meath, Ireland. Community Dent Health 2003;20:146-152.

14. Carlos D, Noel KC, et al. Assessment of retention rates and Clinical benefits of a community sealant program. Pediatr Dent 2005;27(3):212-216.

15. Waggoner WF. Managing occlusal caries of young permanent molars. J Am Dent Assoc 1991;122(11):72-76. DOI: 10.14219/jada. archive.1991.0298.

16. Rock WP, Gordon PH, et al. The effect of operator variability and patient age on the retention of fissure sealant resin. $\mathrm{Br}$ Dent J 1978;145:72-75. DOI: 10.1038/sj.bdj.4804121.

17. Walker J, Floyd C, et al. The effectiveness of sealants in pediatric patients. J Dent Child 1996;63:268-270.

18. Francis $\mathrm{R}$, Mascarenhas $A K$, et al. Retention and effectiveness of fissure sealants in Kuwaiti school children. Community Dent Health 2008;25:211-215.

19. Shashikiran ND, Subbareddy VV, et al. A clinical comparison of visible light activated unfilled, fluoride and non-fluoride containing and filled fluoride containing pit and fissure sealants. J Cons Dent 2004;7:70-76.

20. Lygidakis NA, Oulis KI. A comparison of fluoroshield with delton fissure sealant: four year results. Pediatr Dent 1999;21(7):429-431.

21. Vineet $D$, Tandon $S$. Comparative evaluation of marginal integrity of two new fissure sealants using invasive and non-invasive techniques: a SEM study. J Clin Pediatr Dent 2000;24:291-297. DOI: 10.17796/ jcpd.24.4.74hx73111705213j.

22. Simonsen RJ. Retention and effectiveness of dental sealant after 15 years. J Am Dent Assoc 1991;122(10):34-42. DOI: 10.14219/jada. archive.1991.0289.

23. Vineet $D$, Haiyen $C$. Evaluation of resin based and glass ionomer based sealants placed with or without tooth preparation-A two year clinical trial. Pediatr Dent 2012;34:46-50.

24. Wendt LK, Koch $G$, et al. On the retention and effectiveness of fissure sealant in permanent molars after 15-20 years: a cohort study. Community Dent Oral Epidemiol 2001;29:302-307. DOI: 10.1034/j.1600-0528.2001.290410.x.

25. Autio-Gold JT. Clinical evaluation of a medium-filled flowable restorative material as a pit and fissure sealant. Oper Dent 2002;27:325-329.

26. Rock WP, Weatherill S, et al. Retention of three fissure sealant resins: the effects of etching agent and curing method: results over 3 years. Br Dent J 1990;168:323-324. DOI: 10.1038/sj.bdj.4807185.

27. Handelman SL, Leverett $\mathrm{DH}$, et al. Retention of sealants over carious and sound tooth surfaces. Community Dent Oral Epidemiol 1987;15(1):1-5. DOI: 10.1111/j.1600-0528.1987.tb00470.x.

28. Prabhakar AR, Sankriti A, et al. Comparative evaluation of the length of resin tags, viscosity and microleakage of pit and fissure sealants an in vitro SEM study. Contemp Clin Dent 2011;2(4):324-330. DOI: 10.4103/0976-237X.91797.

29. Morgan MV, Adams GG, et al. Assessing sealant retention using a Poisson frailty model. Community Dent Health 2005;22:237-245.

30. Subramaniam P, Konde $S$, et al. Retention of a resin-based sealant and a glass ionomer used as a fissure sealant: a comparative clinical study. J Indian Soc Pedod Prevent Dent 2008;114-120. DOI: 10.4103/09704388.43192. 